\title{
Reaproveitamento de resíduos agroindustriais de casca banana para tratamento de efluentes
}

\section{Reuse of agroindustrial waste banana peel for wastewater treatment}

\author{
Wanessa Alves Martins ${ }^{1}$, Andréa Maria Brandão Mendes de Oliveira ${ }^{2}$, Carlos Eduardo Pereira de Morais ${ }^{3}$, Luiz Fernando de \\ Oliveira Coelho ${ }^{4}$, Jeanne Freire de Medeiros ${ }^{5}$
}

Resumo: A casca da banana é um resíduo proveniente da agroindústria. Trata-se de um material biodegradável, com baixo custo e apresenta afinidade por compostos orgânicos e metais tóxicos. Neste trabalho avaliou o potencial adsortivo da casca da banana na remoção de chumbo em efluentes. Inicialmente foi preparado o adsorvente e adsorvato, em seguida as amostras foram caracterizadas pelas técnicas FTIR, MEVe TG/DSC. Posteriormente, foram testadas na adsorção do íon chumbo. Foram observados os grupos funcionais presentes na casca da banana como a lignina, celulose e hemicelulose. Os melhores resultados de adsorção ocorreram à $50{ }^{\circ} \mathrm{C}$ com aproximadamente $99,6 \%$. Dessa forma foi possível concluir que a casca da banana além de ser um bom adsorvente natural tem viabilidade para ser utilizado como material alternativo pelo seu baixo custo, facilidade de manuseio e seletividade.

Palavras-Chave:adsorção, íon metálico, biossorção

\begin{abstract}
The banana peel is a residue from the agroindustry. It is a biodegradable material, with low cost and presents affinity for organic compounds and toxic metals. In this research, the potential adsorption of banana peel was evaluated for removal of ion lead in wastewater. Initially was prepared the adsorbent and adsorbate, subsequently all samples were characterized by techniques FTIR, MEV and TG/DSC. Subsequently, they were tested ion adsorption lead.Functional groups present on banana peel as lignin, cellulose and hemicellulose were observed. Adsorption best results occurred at $50{ }^{\circ} \mathrm{C}$ with approximately $99.6 \%$. Thus it was concluded that the banana peel besides being a natural adsorbent has good feasibility to be used as an alternative material for its low cost, ease of handling and selectivity.
\end{abstract}

Keywords: adsorption, metal ion, biosorption

\footnotetext{
*Autor para correspondência

Recebido para publicação em 22/01/2015; aprovado em 25/03/2015

${ }^{1}$ Aluna do Curso de Engenharia Ambiental - Universidade Federal de Campina Grande - UFCG/UACTA, Campus Pombal PB - Rua Jairo Viera Feitosa, n

1770, Bairo dos Pereiros, CEP: 58840-000. E-mail: wanessa_ufcg@hotmail.com

${ }^{2}$ Engenharia Quimica, Professora Doutora - Universidade Federal de Campina Grande - UFCG/UACTA, Campus Pombal PB - Rua Jairo Viera Feitosa, n

1770, Bairo dos Pereiros, CEP: 58840-000. e-mail: andrea.maria@ufcg.edu.br

${ }^{3}$ Aluno do Curso de Engenharia Ambiental - Universidade Federal de Campina Grande - UFCG/UACTA, Campus Pombal PB - Rua Jairo Viera Feitosa, n

1770, Bairo dos Pereiros, CEP: 58840-000. E-mail: carlospereira.sjp@gmail.com

${ }^{4}$ Técnico em Química - Universidade Federal de Campina Grande - UFCG/UACTA, Campus Pombal PB - Rua Jairo Viera Feitosa, n 1770, Bairo dos

Pereiros, CEP: 58840-000. E-mail: luisfoc@ccta.ufcg.edu.br

${ }^{5}$ Técnico em Química - Universidade Federal de Campina Grande - UFCG/UACTA, Campus Pombal PB - Rua Jairo Viera Feitosa, n 1770, Bairo dos

Pereiros, CEP: 58840-000. E-mail: jeannefreire@yahoo.com.br
} 


\section{INTRODUÇÃO}

A preservação do meio ambiente e de seus recursos naturais é necessário para a permanência da vida em nosso planeta. Essa preservação está suportada em coluna como o não desperdício dos bens naturais e a adequação da atividade humana no sentido de reduzir as quantidades de resíduos gerados em seus processos produtivos. A atividade industrial é responsável por gerar um volume significativo de resíduos contendo diversas espécies nocivas à saúde humana e ao ambiente. Geralmente, esses resíduos são líquidos e necessitam de tratamento antes de serem despejados nos corpos hídricos e/ou nos solos. Entre as espécies de maior importância toxicológica presentes nos efluentes industriais estão os metais tóxicos. Esses poluentes não se degradam pela ação do tempo sendo bioacumulados em organismos vivos, podendo causar graves danos à saúde humana (VAGHETTI, 2009).

De acordo com as normas vigentes o lançamento de quaisquer resíduos só poderá acontecer desde que atendam ás condições dispostas na resolução. Para que as indústrias possam atender as normas estabelecidas pelas leis ambientais e minimizar os impactos gerados aos ecossistemas, vários métodos de tratamento de efluentes podem ser empregados (THEODORO, 2010).

Um método versátil e eficaz na remoção de metais pesados tóxicos em solução aquosa é a adsorção (SILVA, 1995; FOLEGALTI, 2004). Os adsorventes mais utilizados na remoção de vários compostos orgânicos e íons metálicos são de alto custo e/ou de natureza impactante com relação ao meio ambiente. Desta forma a busca de novos materiais alternativos de baixo custo, de fonte renovável, de fácil manuseio, de alta eficiência e menor impacto ambiental quando descartados são extremamente almejados (CRUZ, 2009).

Despejos de efluentes industriais sólidos, líquidos ou gasosos, lançam cada vez mais metais pesados e tóxicos no meio ambiente comprometendo a qualidade das águas, do ar, do solo e dos alimentos e, consequentemente, ameaçando o equilíbrio e a estabilidade dos ecossistemas (YAMAMURA, 2009), entretanto a geração de resíduos não é exclusividade das indústrias, uma vez que em laboratórios de universidades, escolas e institutos de pesquisa também são gerados resíduos de elevada diversidade e volume reduzido (ASHBROOK \& REINHARDT, 1985).

Segundo Vaghetti (2009), esses resíduos são líquidos e necessitam de tratamento antes de serem despejados em águas naturais e/ou nos solos. Esses poluentes não se degradam pela ação do tempo sendo bioacumulados em organismos vivos, podendo causar graves danos à saúde humana.

Os metais pesados são altamente reativos do ponto de vista químico, o que explica a dificuldade de encontrá-los em estado puro na natureza. Quando estes compostos são encontrados no meio aquático, sua presença é atribuída às diversas atividades industriais (SALVADOR, 2009). Se os forem ingeridos além da concentração tolerada, podem causar graves distúrbios à saúde humana. A redução dos problemas de saúde pública causados pela presença de metais tóxicos está intimamente relacionada à minimização das emissões de rejeitos industriais que contenham íons metálicos (VAGHETTI, 2009).

Os metais pesados não são biodegradáveis e reagem com ligantes difusores, com macromoléculas e com ligantes presentes em membranas o que, às vezes, lhes conferem as propriedades de bioacumulação, biomagnificação na cadeia alimentar, persistência no ambiente e distúrbios nos processos metabólicos dos seres vivos. As bioacumulações e biomagnificações se incumbem na transformação das concentrações consideradas normais em concentrações tóxicas para diferentes espécies da biota e para o homem. De acordo com Tavares (1992), os efeitos ao longo prazo, mesmo depois de interrompidas as emissões ocorrem devido à persistência.

Os biossorventes oferecem na sua parede celular uma grande variedade de grupos orgânicos tais como ácidos carboxílicos, fenóis e aminas, que podem reter os adsorvatos por complexação, troca iônica, microprecipitação na superfície do biossorvente; e ainda esses biossorventes são materiais ricos em celulose, hemicelulose e pectina, servindo para a adsorção de compostos orgânicos (iônicos ou não) por interação hidrofóbica e forças de van der Waals (VAGHETTI, 2009).

Os biossorventes são originários de alguma forma biológica, como microorganismos vegetais, crustáceos ou animais. Toda biomassa, seja ela ativa (com atividade metabólica) ou inativa (sem atividade metabólica) é tida como biossorvente (BROOKS 1998 apud MOREIRA 2010).

A principal vantagem dos biossorventes com relação aos adsorventes sintéticos, é que os adsorventes de origem natural são abundantes, e por serem resíduos agrícolas, não oferecem valor comercial. Estes biossorventes são fibrosos, de tal forma que seus sítios ativos ficam mais disponíveis para a adsorção de espécies químicas de interesse (adsorvato), desta forma, os biossorventes apresentam capacidades de adsorção comparáveis aos adsorventes comerciais (VAGHETTI, 2009).

O processo de adsorção surge como uma técnica de grande significância para o tratamento de efluentes industriais e/ou laboratoriais, principalmente devido à utilização de adsorventes naturais, onde estes na maioria das vezes são obtidos de subprodutos da indústria ou da agricultura (BATISTA,et al., 2012).

A adsorção pode ser avaliada quantitativamente através de isotermas, as quais permitem estudar a capacidade de adsorção e a força com a qual os metais se ligam a um determinado adsorvente (SALEHIZADEH \& SHOJAOSADATI, 2003). Uma isoterma de adsorção mostra a quantidade de um determinado soluto adsorvido por uma superfície adsorvente, em função da concentração de equilíbrio do soluto (VEGLIO et al., 2003; DURSUN, 2006).

No Brasil, a banana é cultivada em todos os Estados, desde a faixa litorânea até os planaltos do interior, em altitudes que variam de zero a mais de mil metros (FRANCISCO, 2011). O uso da casca de banana como adsorvente diminui o impacto ambiental de duas formas, ou seja, a biomassa residual que muitas vezes torna-se um poluente pelo acúmulo é retirada do local onde é gerada ou depositada e as águas residuárias podem ser tratadas com esta biomassa (BONIOLO,2008).

A casca de banana contém vários sítios de adsorção já ocupados por íons metálicos adsorvidos durante a formação da fruta. Sendo assim se torna imperativo liberar o maior número de sítios ocupados para que a adsorção de metais pesados possa ocorrer em valores maiores possíveis (CRUZ, 2009).

Diante desta necessidade surgem os biossorventes originários de restos do setor agroindustrial para remediação 
de efluentes contaminados solucionando ao mesmo tempo os problemas de destinação dos resíduos agroindustriais e a redução de custos para a descontaminação de efluentes carregados com íons metálicos tóxicos (VAGHETTI, 2009).

Desta forma o objetivo deste trabalho é avaliar o capacidade de adsorção da casca da banana (musa ssp) in natura na remoção de chumbo em efluentes.

\section{MATERIAL E MÉTODOS}

\section{Adsorvato}

A solução metálica de chumbo foi obtida através da dissolução do sal de nitrato de chumbo em água deionizada. Fora preparado $1,0 \mathrm{dm}^{3}$ da solução de nitrato de chumbo na concentração de $0,01 \mathrm{~mol} / \mathrm{dm}^{3}$.

\section{Adsorvente}

O material adsorvente utilizado em todos os experimentos de adsorção foi à farinha da casca da banana obtida na condição otimizada de secagem $\left(65^{\circ} \mathrm{C}\right.$ e $\left.2,0 \mathrm{~m} \mathrm{~s}^{-1}\right)$. $\mathrm{Na}$ temperatura de $65{ }^{\circ} \mathrm{C}$ tem-se assegurado as propriedades da casca da banana evitando a perda de massa podendo ser verificado na análise térmica. As cascas da banana foram coletadas na Indústria de Doce Campo Verde localizada na cidade de Pombal - PB.

As cascas coletadas foram lavadas com água corrente e cortadas em pedaços de aproximadamente $5 \mathrm{~cm}$ de comprimento. Em seguida o material foi posto para secar por três dias ao sol, totalizando 20 horas e posteriormente transferidas para estufa de secagem com circulação de ar com temperatura de $65^{\circ} \mathrm{C}$ por 2 dias, totalizando 24 horas. Após a secagem o material fora triturado em moinho de facas e peneirado para obtenção de frações composta de partículas com tamanho entre 0,15 a $1,18 \mathrm{~mm}$.

\section{Espectroscopia de absorção na região do infravermelho}

A espectroscopia no infravermelho buscou determinar as frequências de vibrações dos grupos funcionais presentes na farinha da casca da banana na faixa de comprimento de onda de 4000 a $400 \mathrm{~cm}^{-1}$. A amostra do adsorvente foi previamente seca em estufa a $65 \pm 2{ }^{\circ} \mathrm{C}$ e analisada com tamanha de partícula $\leq 0,15 \mathrm{~mm}$. A análise foi realizada em espectrofotômetro infravermelho com transformada de Fourier ((FTIR) . A aquisição dos espectros foi feita com a resolução de $4 \mathrm{~cm}^{-1}$, com um número de 30 acumulações utilizando pastilhas de $\mathrm{KBr}$ com $1 \%$ em massa da amostra.

A partir do espectro no infravermelho obtido para a farinha da casca da banana pode-se identificar a presença de bandas características de ligações de certos grupos funcionais presentes no material. Como cada composto fornece uma banda em uma determinada frequência de onda, a análise do espectro é realizada por comparação com dados tabelados, permitindo obter informações estruturais da farinha da casca da banana.

\section{Microscopia eletrônica de varredura}

A análise foi realizada após a secagem da farinha da casca da banana em estufa $65 \pm 2^{\circ} \mathrm{C}$. A Microscopia Eletrônica de varredura permite a análise de superfície possibilitando a análise de falhas e o mapeamento químico de superfícies.

As imagens de microscopia de varredura foram obtidas em microscópio eletrônico de varredura após a metalização das amostras em ouro e paládio. A microscopia eletrônica de varredura (MEV) buscou investigar a morfologia superficial da farinha da casca de banana.

\section{Análise termogravimétrica}

A análise foi realizada após secagem da farinha da casca de banana em estufa $65 \pm 2{ }^{\circ} \mathrm{C}$. A farinha da casca da banana pura foi caracterizada por análise termogravimétrica. As curvas termogravimétricas (TG) foram obtidas em uma termobalançada interfaciada ao computador sob razão de aquecimento programada em $10 \mathrm{~K} \mathrm{~min}^{-1}$, numa atmosfera de nitrogênio na faixa de temperatura de 300-1239 K.

As técnicas termoanalíticas são métodos que permitem estabelecer a função entre propriedades físicas e químicas de uma substância ou mistura em relação à temperatura ou tempo, quando submetida a temperaturas controladas.

A análise termogravimétrica (TG/DSC) avalia a perda de massa de uma amostra em atmosfera controlada em função da temperatura ou do tempo. Essa análise permite determinar a pureza e a quantidade de água, fornecendo ainda informações sobre a estabilidade térmica, velocidade de reação e composição da amostra.

\section{Determinação das isotermas de troca iônica na farinha da casca da banana}

\section{Isoterma de Tempo}

Utilizou-se o método de batelada para a obtenção da isoterma de tempo em meio aquoso a fim de se fixar o tempo máximo de contato para maior adsorção do íon metálico. A isoterma fora obtida pelo contato de $1 \mathrm{~g}$ do sólido, medidas em balança analítica com sensibilidade $0,0001 \mathrm{~g}$, suspensas em $20,0 \mathrm{~cm}^{3}$ da solução aquosa do íon metálico de $0,01 \mathrm{~mol} / \mathrm{dm}^{3}$. A suspensão a 298,15 K foi, então, mecanicamente agitada em incubadora tipo shaker com rotação de $180 \mathrm{rpm}$ em tempos variados. Após os tempos pré-estabelecidos, as suspensões foram filtradas e as alíquotas do sobrenadante foram removidas, com o auxílio de uma pipeta, sendo a quantidade do cátion metálico determinados através do espectrofotômetro de absorção atômica. Assim pode-se determinar a quantidade de cátion trocado $\left(\mathrm{N}_{\mathrm{f}}\right)$ por grama de farinha de casca de banana pela diferença entre a quantidade de cátion inicial (Ni) e aquela presente após o equilíbrio (Ns) conforme a equação (Eq. 1).

$$
N_{f}=\frac{\left(N_{i}-N_{s}\right)}{m}
$$

\section{Isoterma de concentração}

Estabelecido o tempo da reação e dosagem do sólido, a influência da concentração do cátion metálico foi avaliada, adotando-se o mesmo procedimento da isoterma de tempo, utilizando concentrações crescentes do cátion metálico na 
faixa entre $10^{-3}$ a $10^{-2}$ mol.dm ${ }^{-3}$ em três temperaturas 27,40 e $50{ }^{\circ} \mathrm{C}$.

\section{RESULTADOS E DISCUSSÃO}

\section{Caracterização das amostras}

Análise por espectroscopia no infravermelho com transformada de Fourier

A capacidade de remoção de metais pela casca de banana depende da composição química da sua superfície, onde alguns grupos funcionais ativos são responsáveis pela sorção. A Tabela 1 apresenta as atribuições das bandas características obtidas na faixa de 4000 a $400 \mathrm{~cm}^{-1}$ para a casca da banana

Tabela 1- Frequência no infravermelho das bandas de alguns grupos funcionais presentes na casca de banana.

\begin{tabular}{ll}
\hline Frequência $\left(\mathrm{cm}^{-1}\right)$ & Grupos funcionais \\
\hline 3433,1 & $-\mathrm{OH},-\mathrm{NH}$ \\
2927,7 & $-\mathrm{CH}$ \\
2360,7 & $-\mathrm{CH}$ \\
1654,3 & $-\mathrm{COO}-,-\mathrm{C}=\mathrm{O}$ \\
1542,9 & $-\mathrm{COO}-, \mathrm{C}-\mathrm{C}$ \\
1049,2 & $-\mathrm{C}-\mathrm{O},-\mathrm{C}-\mathrm{N},-\mathrm{P}=\mathrm{O},-\mathrm{P}-$ \\
& $\mathrm{OH}, \mathrm{P}-\mathrm{O}-\mathrm{C}$ \\
\hline
\end{tabular}

Fonte: Salvador, (2009).

A espectroscopia no infravermelho das amostras da farinha da casca da banana encontra-se apresentadas na Figura 1. A análise visual dos espectros de FTIR permitiu a detecção de um maior conjunto de variáveis de bandas espectrais de FTIR (15 a 20 bandas, 3000-600 ondas.cm ${ }^{-1}$ ) compreendidas neste intervalo de comprimento de onda, nas amostras de farinha da casca de banana. Esse grande número de bandas no espectro sugere uma natureza complexa de absorvente.

De acordo com Cruz (2009) a análise do espectro na região do infravermelho do material FBN sugere a presença de grupos funcionais como: celulose, lignina, ácida peptico, ácidos orgânicos pequenos, ésteres amilícos e proteínas. Os dados obtidos no presente trabalho, motraram comportamento semelhante aos resultados obtidos por Cruz (2009), com diferenças apenas na intensidade dos picos.

Observa-se também que o espectro de infravermelho revelou presença de bandas na região de 3486 e $3286 \mathrm{~cm}^{-1}$ atribuídas a estiramentos vibracionais axiais dos grupos $\mathrm{O}-\mathrm{H}$ característicos da celulose, na região de 2967 e $2843 \mathrm{~cm}^{-1}$ que podem ser atribuídas aos grupos $\mathrm{CH}-\mathrm{OH},-\mathrm{CH}$ e $-\mathrm{CH} 2$ de grupos alifáticos característicos da estrutura da celulose e em $1730 \mathrm{~cm}^{-1}$ é atribuída a vibração de deformação axial de $\mathrm{C}=\mathrm{O}$ de ácidos carboxílicos presentes na casca de banana (ácido péptico ou ácido cítrico) ou de ésteres. A banda intensa em $1641 \mathrm{~cm}^{-1}$ pode ser atribuída a vibração de estiramento do ânion - $\mathrm{COO}^{-}$ou do grupo -C-O- de ésteres. A banda em 1104 $\mathrm{cm}^{-1}$ pode ser atribuída ao estiramento ligado a grupos $-\mathrm{S}-\mathrm{OH}$ ou $-\mathrm{P}=\mathrm{O}$. A banda em $884 \mathrm{~cm}^{-1}$ pode ser atribuída a deformação de aminas.

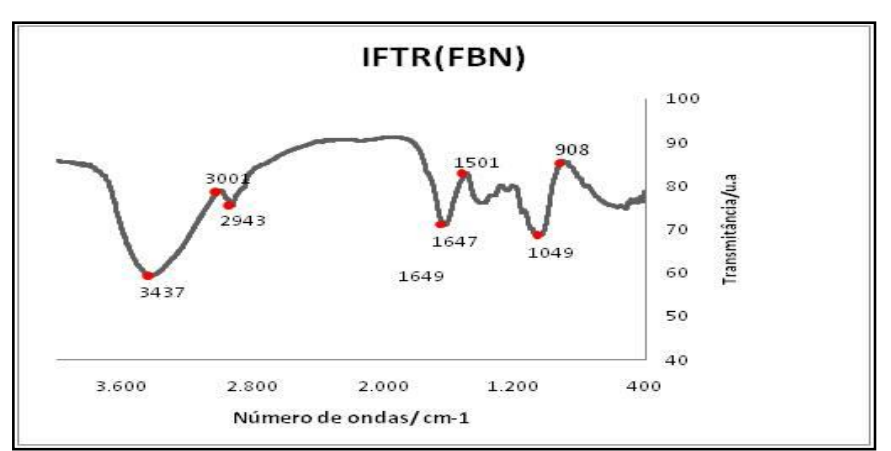

Figura 1-Espectro de infravermelho da farinha da casca de banana.

Fonte: Arquivo pessoal, 2014.

\section{Análise termogravimétrica (TG)}

A Figura 2 apresenta as curvas termogravimétricas (TG) e termogravimétricas derivadas (DTG) para a farinha da casca da banana. Foi observada a ocorrência de três eventos principais. $\mathrm{O}$ primeiro evento corresponde a perda de massa referente à perda da água absorvida do biomaterial no intervalo de temperatura de 0 a $170{ }^{\circ} \mathrm{C}$. No segundo evento ocorre à degradação da hemicelulose e celulose, termicamente menos estáveis que a lignina e ocorre no intervalo de temperatura de 170 a $350^{\circ} \mathrm{C}$. O terceiro evento corresponde a perda de massa com temperatura superior a $350^{\circ} \mathrm{C}$, havendo a quebra das ligações $\mathrm{C}-\mathrm{O}$ e $\mathrm{C}-\mathrm{C}$, liberando $\mathrm{CO}$ e $\mathrm{CO}_{2}$, acima de $400{ }^{\circ} \mathrm{C}$ há a formação de uma camada de grafite. Até $150^{\circ}$ $\mathrm{C}$ ocorre a liberação da água adsorvida, água estrutural e celulose entre $150^{\circ}$ e $240^{\circ} \mathrm{C}$, quebra das ligações $\mathrm{C}-\mathrm{O}$ e C $\mathrm{C}$ dentro do anel, liberando $\mathrm{CO}$ e $\mathrm{CO}_{2}$ entre $240^{\circ}$ e $400^{\circ} \mathrm{C}$ acima de $400{ }^{0} \mathrm{C}$ há a formação de uma camada de grafite (SOUSA et al, 2006).

Os eventos térmicos observados correspondem às perdas de massa indicadas nas curvas TG/DTG e estão de acordo com aqueles apresentados na curva DSC nesta pode ser observado um evento endotérmico entre 23 e $50^{\circ} \mathrm{C}$, que começa haver a libertação de água de umidade. A partir de 50 ${ }^{\circ} \mathrm{C}$ observaram-se eventos caracteristicamente exotérmicos, onde ocorre a perda de toda a água do biomaterial além do inicio da decomposição térmica do material que se complementa a partir de $400{ }^{\circ} \mathrm{C}$.

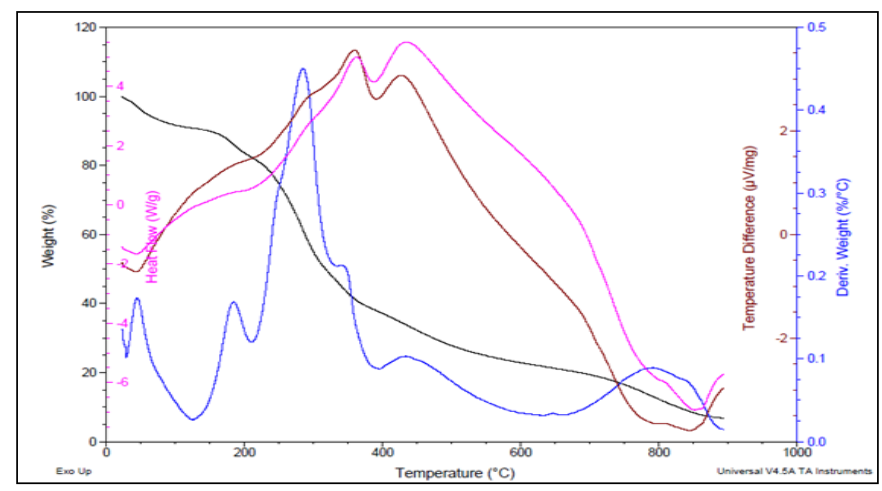

Figura 2- Curvas das análises de TG e DSC da farinha da casca de banana.

Fonte: Arquivo pessoal, 2014. 


\section{Tg com o Chumbo}

A Figura 3 apresenta a análise termogravimétrica da casca da banana após o processo de troca iônica. É possível observar que da mesma forma de identificou na casca da banana natural com o chumbo, ocorreu três etapas de decomposição térmica, verificando que as curvas termogravimétricas do material natural e do sólido com o cátion metálico apresentam perfis semelhantes.

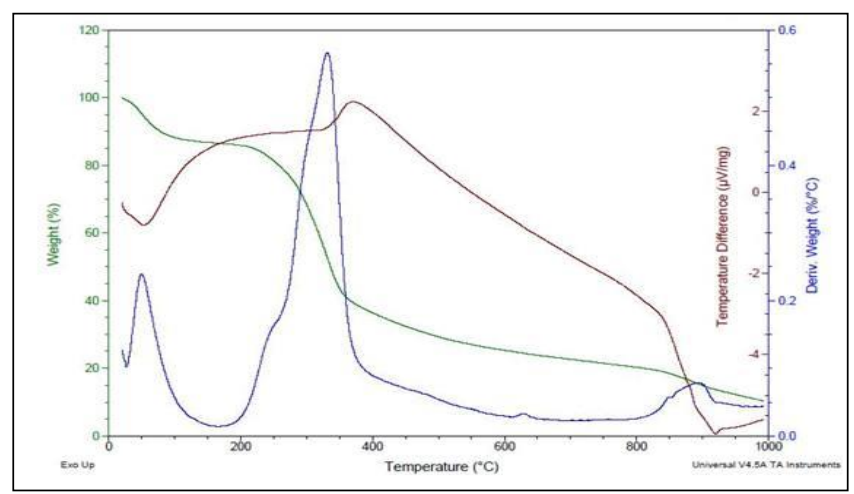

Figura 3-Curvas das análises de TG e DSC da farinha da casca de banana em contado com o Chumbo.

Fonte: Arquivo pessoal, 2014.

\section{Análise por microscopia eletrônica de varredura}

As microscopias das amostras de farinha da casca da banana foram apresentadas na Figura 4.

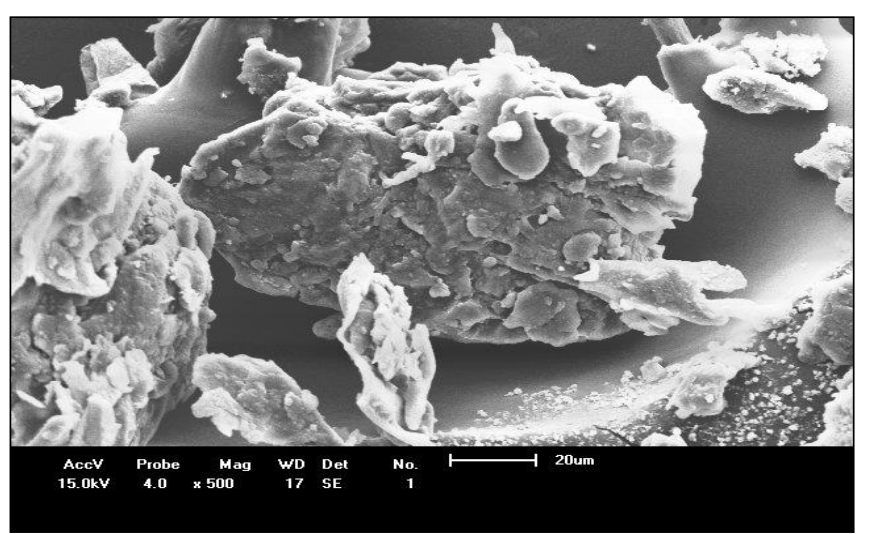

Figura 4-Micrografia da farinha da casca de banana.

Fonte: Arquivo pessoal,2014.

Na figura acima foi ampliada 500 vezes, pode ser notada a estrutura fibrosa e irregular da farinha da casca de banana natural (FBN) formando camadas sobrepostas de fibras, sendo possível notar grãos menores agregados aos grupos maiores. A superfície irregular e a morfologia porosa como podem ser vista na micrografia facilitam a adsorção de metais em solução aquosa, permitindo uma boa remoção destes nas diferentes partes da FBN.

Para verificar a presença de íons de chumbo na farinha da casca de banana, após processo de biossorção foram realizadas análises com o microscópio eletrônico de varredura (MEV), as amostras apresentavam um tamanho de partícula de $250 \mathrm{~mm}$. Pode-se observar uma ligeira redução na quantidade de poros livres conforme observado figura 5 , quando comparado a figura 4 , isso se deve a ocupação dos espaços porosos pela espécie metálica, o que induz que a farinha da casca de banana, realmente tem bom potencial adsortivo para o metal pesquisado.

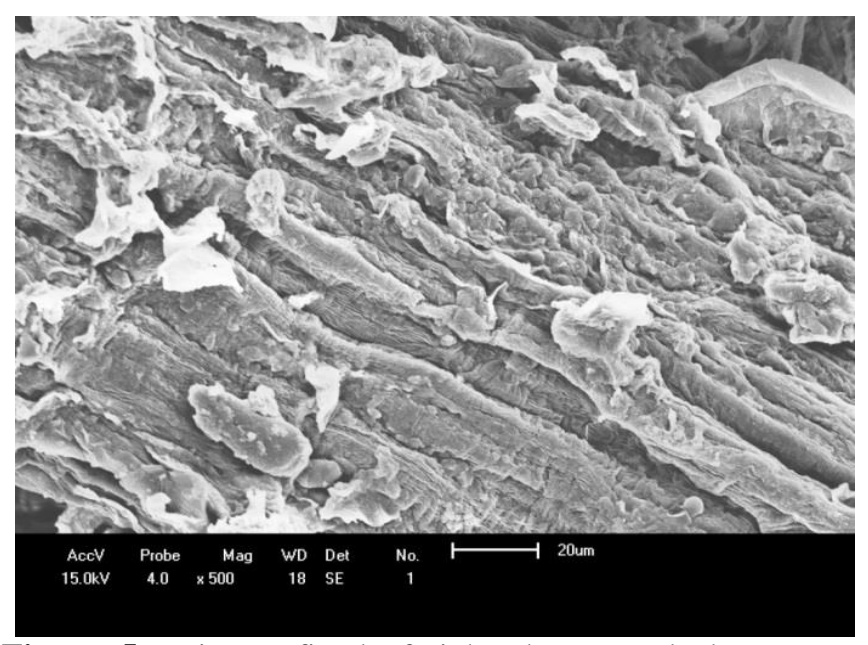

Figura 5- Micrografia da farinha da casca de banana em contato com o chumbo.

Fonte: Arquivo pessoal,2014.

\section{Influência do tempo}

A influência do tempo de contato entre o íon em solução e o adsorvente é de suma importância para a eficiência do processo,sendoalcançado quando o sistema entra em equilíbrio. Assim, o efeito do tempo de contato para a adsorção do íon $\mathrm{Pb}^{2+}$ na casca de banana pode ser visualizada na Figura 6.

Observando a Figura referente à interação do sólido com o chumbo percebe-se que houve uma rápida adsorção nos primeiro minutos, seguido por um gradual equilíbrio. Isso mostra que a adsorção máxima para o $\mathrm{Pb}$ (II) ocorreu em 10 minutos e que quase não há retenção além desse período. Assim, o tempo de reação de $10 \mathrm{~min}$ foi fixado como o tempo de equilíbrio ao longo desse estudo.

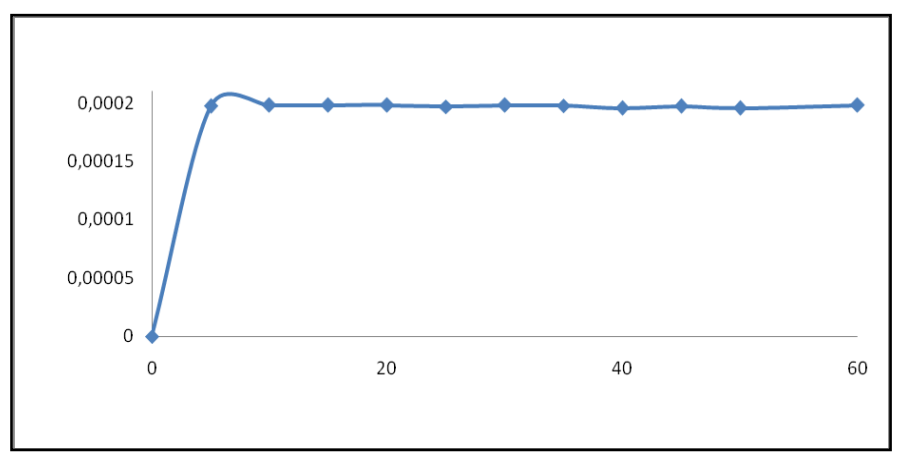

Figura 6- Influência do tempo de contato na adsorção do chumbo pela farinha da casca de banana.

Fonte: Arquivo pessoal, 2014.

\section{Influência da concentração}

Uma isoterma de adsorção mostra a relação de equilíbrio do adsorbato no adsorvente e na solução em determinada temperatura e pressão. As isotermas de adsorção indicam como o adsorvente efetivamente adsorverá a espécie 
de interesse, bem como apresentar uma estimativa máxima da capacidade de adsorção.

Com o objetivo de conhecer a eficiência do adsorvente, foram determinadas as isotermas de adsorção. Dessa forma, com o tempo de equilíbrio definido, foi possível construir essas isotermas e calcular o percentual de cátion adsorvido pela casca da banana, em diferentes condições operacionais. As isotermas de $\mathrm{Pb}$ (II) nas temperaturas 27, 40 e $50^{\circ} \mathrm{C}$ estão ilustrada na Figura 7.

Observou-se que as isotermas seguiram basicamente o mesmo comportamento crescente nas três temperaturas estudadas. A capacidade máxima de adsorção de $\mathrm{Pb}$ (II) foi de aproximadamente 95,$2 ; 98$ e 99,6 \% nas temperaturas de $27^{\circ} \mathrm{C}$ para $\mathrm{T} 1,40^{\circ} \mathrm{C}$ para $\mathrm{T} 2$ e $50{ }^{\circ} \mathrm{C}$ para $\mathrm{T} 3$, respectivamente.

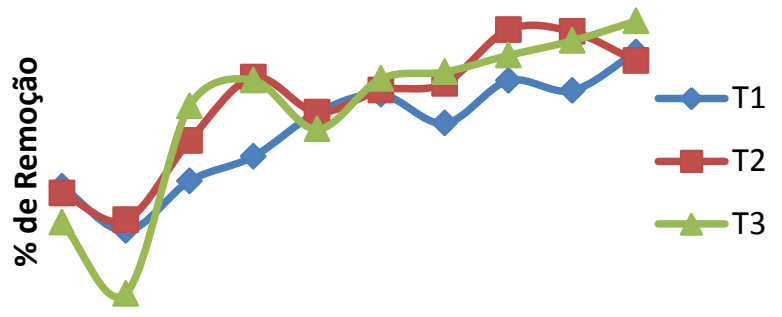

Concentração de $\mathrm{Pb}$ (mg L-1)

Figura 7-Isoterma de concentração do íon do chumbo com $\mathrm{Ph} 5$.

Fonte:Arquivo pessoal,2014.

\section{CONCLUSÕES}

Nesse trabalho foram investigados os processos de troca iônica envolvendo a casca da banana e o íon metálico $\mathrm{Pb}$ (II) em solução aquosa. Foi observado que diversos fatores experimentais estão envolvidos neste processo de adsorção podendo destacar como fator primordial o tempo de reação.

$\mathrm{O}$ tempo de 10 minutos para a remoção do $\mathrm{Pb}$ (II) foi escolhido por não apresentar uma variação significativa após este tempo.

A caracterização da casca da banana foi realizada através do espectro no infravermelho (FTIR), onde apresentou grupos funcionais comuns à celulose, hemicelulose e lignina presentes na casca da banana.

A termogravimetria (TGA) e termogravimetria derivada (DTG) demonstrou a ocorrência de três estágios de perda de massa relativos a umidade, hemicelulose e lignina.

A casca da banana demonstrou ser um bom adsorvente natural para o íon metálico investigado com ótima capacidade de remoção do metal, se mostrando atrativo por se tratar de um subproduto agroindustrial tendo em vista sua facilidade de manuseio, baixo custo e seletividade. Portanto, este biossorvente pode ser utilizado como material alternativo.

\section{REFERÊNCIAS BIBLIOGRÁFICAS}

ASHBROOK, P.C.; REINHARDT, P.A.; Environ. Sci. Technol. 1985, 19, 1150.

BATISTA,T.S.; LIRA,T.K.B.; SOUZA,J.S.B.; BARROS, T.R.B.; LIMA,V.E. Remoção de chumbo(ii) em efluentes utilizando diferentes biomassas adsorventes.Encontro Nacional de Educação, Ciência e Tecnologia/UEPB.2012.10f.

BONIOLLO, M.R., Biossorção de Urânio nas cascas de banana.2008.121f. Dissertação (Mestre em Ciências na Área de Tecnologia Nuclear)-Instituto de Pesquisa Energética e Nucleares, São Paulo-SP.

BOSCH NETO, J.C.; GOMES, P.M.C.; SEGALL, S.D.; FERREIRA, A.G.; CHARBEL, A.T.; AZADINHO, A.; CARNEIRO, G.; CALDEIRA, E.; AIRES, L. Obtenção da farinha da casca da banana através de um secador solar e da moagem em um moinho de bolas de baixo custo - valor nutricional e possibilidades na indústria de alimentos. In: $6^{\circ}$ SIMPÓSIO LATINO AMERICANO DE CIÊNCIA DOS ALIMENTOS, 2005, Campinas. Anais... Petrolina: UNICAMP. CD-ROM. 2005.

CRUZ, M.A.R.F. da.,Utilização da casca de banana como biossorvente.2009. 74f. Dissertação (Mestrado em Química dos Recursos naturais)-Universidade Estadual de Londrina, Londrina-PR.

DURSUN, A. Y.; Biochem Eng. J.2006, 28, 187.

FRANCISCO, M. S., Diagnóstico da produção e qualidade dos frutos de banana (Musa spp), cultivada no município de Bananeiras - PB/ Maria Sueli Francisco. - Bananeiras, 2011.

FOLEGATTI, M. I. S., et al. Banana processamento. Embrapa mandioca efruticultura tropical, 2004. Disponível

em: <http://www.agencia.cnptia.embrapa.br/recursos/Liv ro Banana_Cap_13IDPA3643xufd.pdf $>$. Acesso em: 12 de Julho de 2014.

MOREIRA, D. R. Desenvolvimento de adsorventes naturais para tratamento de efluentes de galvanoplastia. 2010,79f. Dissertação (Mestrado em Engenharia e Tecnologia de Materiais), Pontifícia Universidade Católica do Rio Grande do Sul, Porto Alegre - RS, 2010.

SALVADOR, G. Estudo da adsorção de cobre (II) usando como adsorvente pó da casca de coco verde ativada com hidróxido de sódio.Universidade Federal De Santa Catarina, 2009. 40f.

SALEHIZADEH, H.; SHOJAOSADATI, S. A.; Water Res.2003, 37, 4231.

SILVA, C. A. B. Produção de banana-passa: perfis agroindustriais. Viçosa: 
Fundação Arthur Bernardes / Universidade Federal de Viçosa /Ministério da Agricultura do Abastecimento e da Reforma Agrária, 1995.

SOUSA, E.; RAMBO, C.R.; MONTEDO, D.H.; OLIVEIRA, A.P.N. Vitrocerâmicas porosas do sistema LZSA utilizando resíduos orgânicos como agentes formadores de poros. Exacta, v. 4, p. 289-296, 2006. Disponível em: http://www.uninove.br/PDFs/Publicacoes/exacta/exacta v4n2/exactav4n2_3f04.pdf> acesso em 03/07/2013.

TAVARES, T. M. Avaliação de Exposição de Populações Humanas a Metais Pesados no Ambiente: Exemplos do Recôncavo Baiano. Química nova, v.15, n.2, p.147154, 1992.

THEODORO, P. S.,Utilização da eletrocoagulação no tratamento de efluentes da indústria galvânica. 2010.112f. Dissertação (Mestrado em Engenharia Química)- Universidade Estadual do Oeste do Paraná, Toledo - PR.

VAGHETTI,J.C.P., Utilização de Biossorvente para remediação de efluentes aquosos contaminados com íons metálicos. 2009. 99f. Tese (Doutorado em Química)-Universidade Federal do Rio Grande do Sul, Porto Alegre-RS.

VEGLIO, F.; ESPOSITO, A.; REVERBERI, A. P.; ProcessBiochem. 2003, 38, 953.

YAMAMURA, A.P.G.; Aplicação de Nanotecnologia no Meio Ambiente: Biossorvente Magnético na Remoção de Urânio. 2009, 117f. Dissertação(Mestrado em Ciências na Área de Tecnologia Nuclear Materiais), Instituto De Pesquisas Energéticas e Nucleares, Autarquia Associada à Universidade de São Paulo, São Paulo - SP, 2009. 